\title{
Pediatric Failure to Thrive
}

National Cancer Institute

\section{Source}

National Cancer Institute. Pediatric Failure to Thrive. NCI Thesaurus. Code C113099.

Less than normal weight gain in an infant or child, which may include poor linear and head growth. 